\title{
Polyvalent Diazonium Polymers Provide Efficient Protection of Oncolytic Adenovirus Enadenotucirev from Neutralising Antibodies while Maintaining Biological Activity In Vitro and
} In Vivo

Nora Francinia, ${ }^{a,}$, Daniel Cochrane ${ }^{b}$, Sam Illingworth ${ }^{b}$, Laura Purdiea, Giuseppe Mantovania $^{\mathrm{a}}$, Kerry Fisher ${ }^{\mathrm{b}, \mathrm{c}}$, Leonard W. Seymour ${ }^{\star \star}$, Sebastian G. Spain ${ }^{\mathrm{d} \star}$ and Cameron Alexander ${ }^{\star *}$

a. School of Pharmacy, University of Nottingham, NG7 2RD, UK. E-mail: cameron.alexander@nottingham.ac.uk; Tel: +44 (0)115 8467678.

b. PsiOxus Therapeutics Limited, 4-10, The Quadrant, Abingdon Science Park, Abingdon, Oxfordshire, OX14 3YS, UK.

c. Department of Oncology, Old Road Campus Research Building, Roosevelt Drive, Oxford, OX3 7DQ, UK. Email: len.seymour@oncology.ox.ac.uk.

d. Department of Chemistry, University of Sheffield, Sheffield, S3 7HF. E-mail s.g.spain@sheffield.ac.uk; Tel: +44 (0)114 222 9362; Twitter: @sebspain.

‡ Present address. IIT Central Research Laboratory, Istituto Italiano di Tecnologia, 16163 Genova, Italy. 

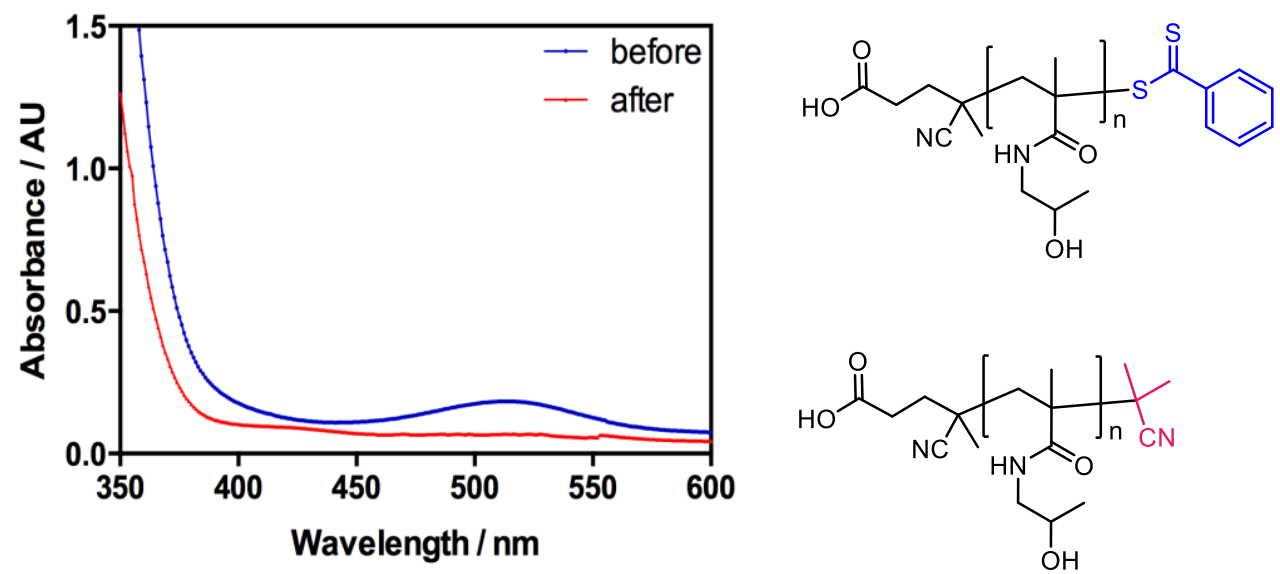

Figure S1. Representative UV/Vis spectra and chemical structures of PHPMA P1 before (blue) and after (red) treatment with AIBN.

(a)

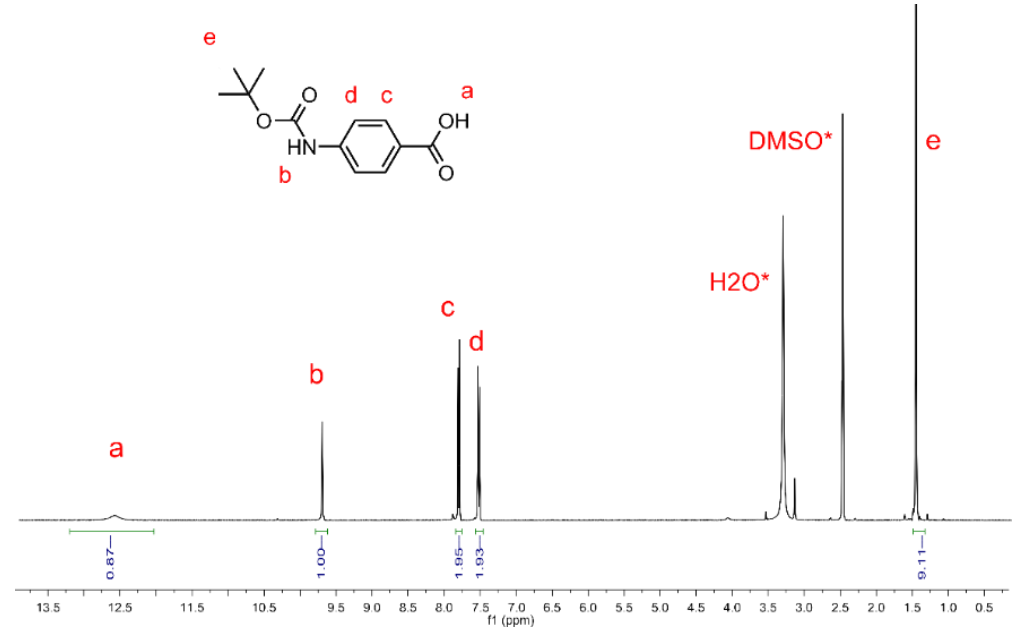

(b)

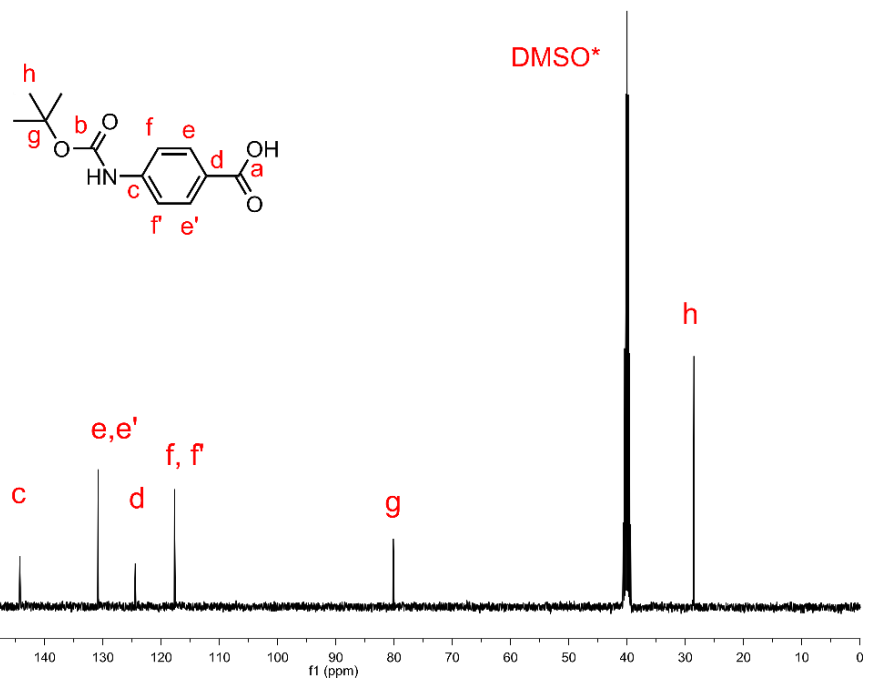

Figure S2 (a) ${ }^{1} \mathrm{H}$ and (b) ${ }^{13} \mathrm{C}$ NMR spectra of $p$-aminobenzoic acid-Boc protected (PABA-boc). 


\section{Conjugation to a BSA}

a)
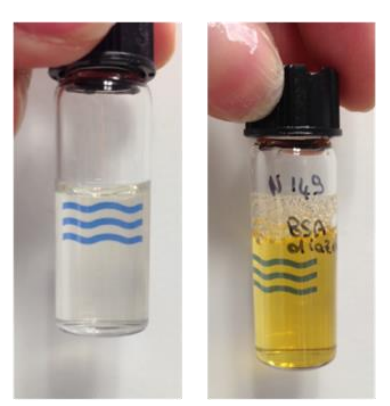

b)

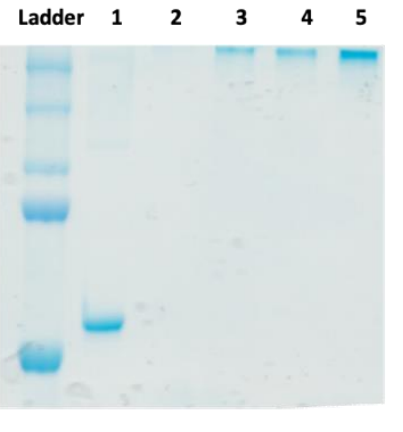

1- BSA; 2- Polymer; 3- 10 eq polymer; 4- 5 eq polymer; 5- 2.5 eq polymer c)

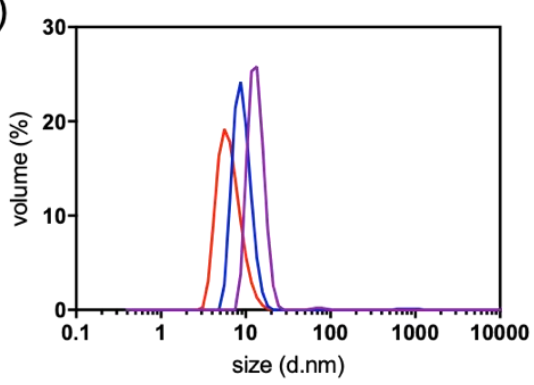

- Conjugate

d)
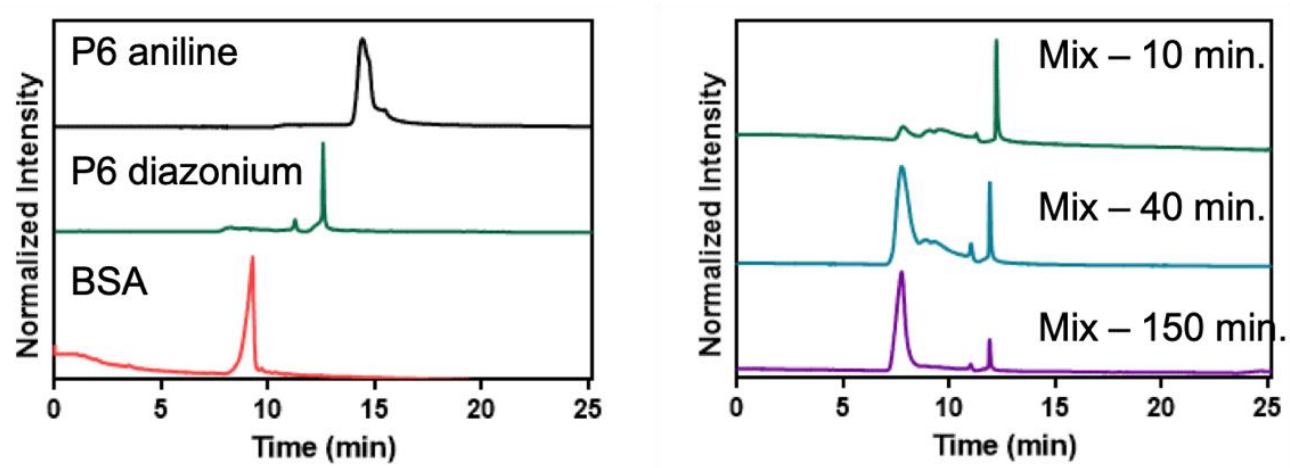

Figure S3 Polydiazonium polymer solutions before and after conjugation of P6 with BSA (24 hours); b) SDS-PAGE, lane 1 ladder, 2 BSA, 3 P21 polymer , 4-6 P6-BSA conjugate at decreasing concentration. c) DLS of P6, BSA and P6-BSA conjugates in $10 \mathrm{mM}$ HEPES pH 7.4; aqueous GPC of activiated P6, BSA and P6-BSA conjugate at different times post mixing.

\section{Metabolic Activity Assay (MTS)}

HT-29 cells were seeded into 96 -well plate at a density of $25 \mathrm{k}$ cell/well in $100 \mu \mathrm{L}$ of assay media. Cells were treated with $1 \mathrm{mg} / \mathrm{mL}$ dilutions of polymer-coated EnAd in assay media and incubated for 2 hours at $37^{\circ} \mathrm{C}, 5 \% \mathrm{CO}_{2}$ before replacing the media with fresh one. After 24 hours incubation, cells were washed with PBS and $120 \mu \mathrm{L}$ of a solution of MTS in phenol-red free assay media (1:6 dilution) added to the well. The plate was incubated for $30 \mathrm{~min}$ at $37^{\circ} \mathrm{C}, 5 \% \mathrm{CO}_{2}$ and the absorbance measured at $40 \mathrm{~nm}$ using Wallac 1420 Victor multi-label counter or BioTek ${ }^{\mathrm{TM}}$ Synergy HT multimodal microplate reader. 


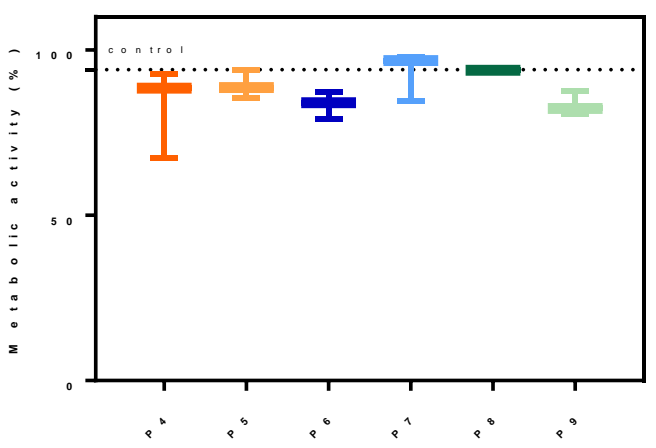

Figure S4. Metabolic activity of HT-29 cells measured by MTS assay 24 post-infection with P4 to P9 on HT-29 cell line. Polymer solution were prepared according to the concentrations required for polymer coating. (Means of triplicate values and standard deviation).
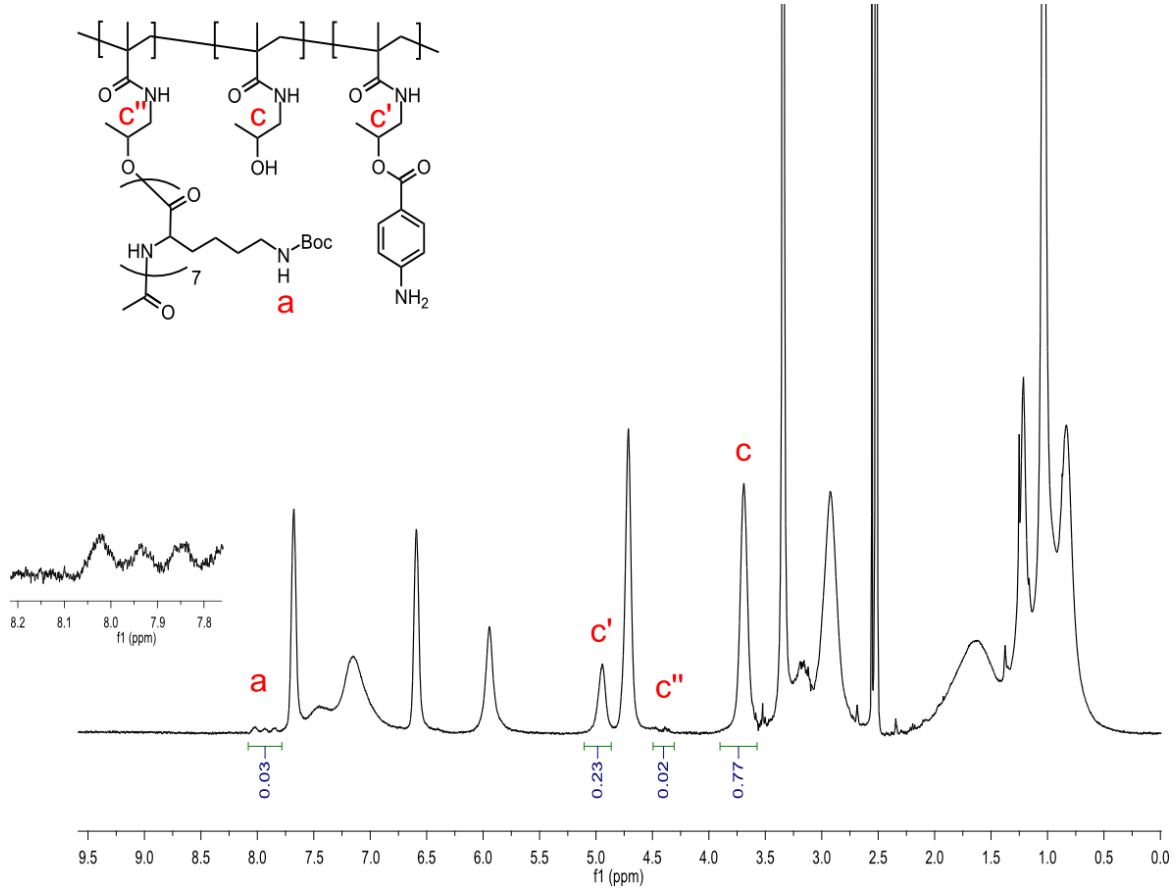

Figure S5. ${ }^{1} \mathrm{H}$ NMR of re-targeted labelled polydiazonium with $\mathrm{K}_{7}\left(\mathrm{P} 9-\mathrm{K}_{7}\right)$ after purification. 


\section{Live Confocal Microscopy}

Uncoated EnAd was fluorescently labelled with a 20-fold molar excess per viral amine (approximately 1800 lysines per particle) of BODIPY-FL (Invitrogen) for 2 hours in 50 mM HEPES buffer at pH 7.4. Samples of polymer-coated EnAd were prepared according to the procedure described in paragraph 5.2 .8 , utilizing a $1 \mathrm{mg} / \mathrm{mL}$ final polymer concentration. Coating efficiency was tested by ELISA before conducting the experiments. $1 \times 10^{5} \mathrm{HT}-29$ cells were seeded on BD poly-L-Lysine glass bottomed 35 $\mathrm{mm}$ dishes and cultivated overnight in assay media. Cells were then washed with ice cold PBS, incubated in ice cold media $\left(1.5 \mathrm{~mL}\right.$ ) before infection with $1 \times 10^{4}$ virus particles (uncoated EnAd or EnAd-P9- FL) for 1 hour over ice. After this time, cells were washed three times with ice cold PBS before addition of $1.5 \mathrm{~mL}$ of ice cold HBSS $20 \mathrm{mM}$ HEPES buffer. The samples were stored on ice until they were placed in the incubation chamber for confocal imaging. Live cell imaging was performed on a LSM 710 (Carl Zeiss) confocal microscope using a $63 \times$ oil immersion objective and a $\mathrm{CO}_{2}$-controlled incubator at $37^{\circ} \mathrm{C}$. Image analysis was performed using Zen Lite and ImageJ softwares. Images were digitized under constant exposure time, gain and offset.

\section{EnAd}
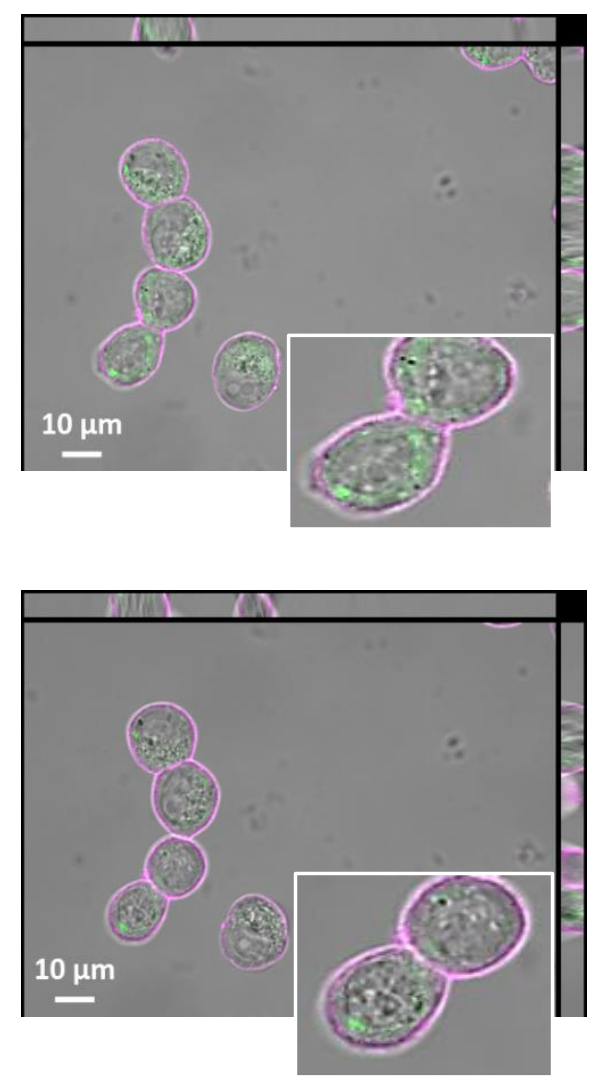

\section{EnAd-P9-FL}
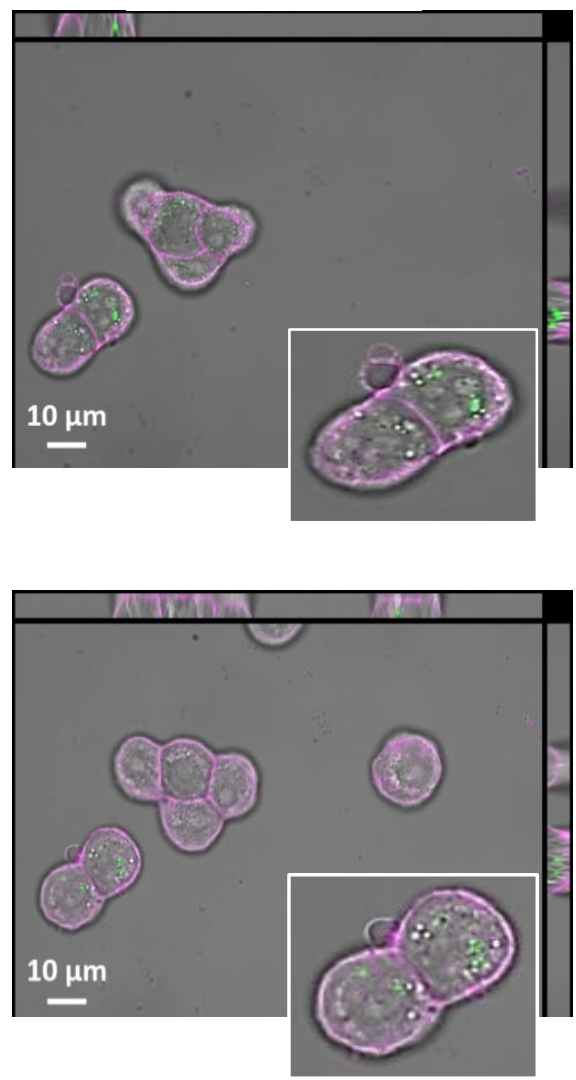

Figure S6. Merged confocal images of EnAd and EnAd-P9-FL at 5 and 60 minutes post-infection. Each ortho visualization was gained from a z-stack consisting of 10 slices, and was used to confirm that in both cases the virus is present within the cell and not at the membrane. Green = EnAd-FL or EnAd-P9-FL; Magenta = cell plasma membrane. 